\title{
Spinal cord oligodendroglioma
}

\author{
A. R. NATHOO \\ M.B., B.S.
N. P. HaLliday
M.B., B.S.

Queen Mary's Hospital, Sidcup

OLIGODENDROGLIOMA of the spinal cord is a rare tumour. We report here a case which presented to us in an unexpected manner.

\section{Case report}

A woman of 45 was brought in to the Casualty Department, Queen Mary's Hospital, Sidcup, in March 1966, having taken ten tablets of Mandrax (each tablet containing $250 \mathrm{mg}$ of methaqualone and $25 \mathrm{mg}$ of diphenhydramine) as a suicidal gesture.

On examination she appeared flushed, unrousable and cyanosed. Her respiratory rate was $12 / \mathrm{min}$, pulse regular at $80 / \mathrm{min}$ and the blood pressure was $120 / 80 \mathrm{mmHg}$. There was nothing else of particular note on general examination. She had a gastric wash-out and following $10 \mathrm{mg}$ of megimide intravenously her respiration improved and she became rousable. Subsequently she had a forced diuresis with $10 \%$ mannitol and her recovery was uneventful. When it became possible to communicate with her, she emerged as a perfectly rational, intelligent housewife, even though somewhat depressed at the time. She was happily married. Further questioning revealed a more complex history. In 1958 she developed acute backache and was diagnosed as having a 'disc lesion' and treated with traction. Her symptoms cleared up and she remained free from backache until 1962, when she began to get attacks of low sacral backache associated with shooting pains down the back of both thighs, left more than right, made worse by coughing and sneezing and relieved by lying down. These attacks lasted from 1 to 3 weeks followed by periods of remission lasting from 1 to 3 months. In 1965 the pain became more severe and was treated with bed rest at home. During this time she was found to have uterine fibroids associated with moderate menorrhagia and it was thought that her backache might have been related to this. Hysterectomy was performed at another hospital in December 1965. Following this, however, her pain persisted, requiring large doses of analgesics to control it. She became progressively depressed and haunted by the thought that she was going to become a complete cripple, which eventually culminated in the suicidal attempt. On re-examination she was markedly tender over the lower lumbar and sacral spine. Straight leg raising was equal and full on both sides. There was no wasting of the limb muscles and the tone and power was equal. The reflexes were brisk in the legs compared to the arms, but equal. The plantar responses were flexor. There was no sensory loss. The rest of the neurological examination was normal. There were no urinary or bowel symptoms.

Investigations: Blood count and ESR normal. $\mathrm{X}$-ray of the lumbo-sacral spine normal. Lumbar puncture: slightly turbid and xanthochromic fluid. The CSF contained more than $2000 \mathrm{mg} / 100 \mathrm{ml}$ of protein with an excess of globulin, 2 lymphocytes, 2 polymorphs and $1400 \mathrm{red}$ cells $/ \mathrm{mm}^{3}$. A diagnosis of cauda equina tumour was suspected and the patient was transferred to the Neurosurgical Department at the Brook General Hospital under the care of Mr Northcroft. Further investigations included a myelogram by cisternal puncture. There was complete obstruction at the level of the body of $\mathrm{L} 1$ where there was a rounded, intrathecal 'extramedullary' tumour displacing the tip of the cord forwards and to the left. The lower limit of the tumour could not be seen.

Operation. On 11 March 1966 a laminectomy was performed, excising the spinous processes and laminae of T12, L1, 2, 3 and 4. There was no extradural tumour. A firm mass was palpable intradurally. After the dura was opened a firm, fleshy tumour covered by arachnoid was seen. It was easy to dissect away the nerve roots at the upper end of the tumour, but midway down on the anterior aspect it was adherent and tended to bleed. Dissection was, therefore, commenced from the lower end. The tumour was a little more adherent to the nerve roots here but separated without undue difficulty. One strand, ? nerve root, ? filum terminale, had to be sacrificed as it was firmly embedded in the tumour. The tumour was removed in one piece. At the end of the operation the compressed cauda equina was seen to be intact, except for one thick strand which lay in the mid-line and appeared to be the upper end of 
the strand sacrificed during the removal of the tumour. The tumour appeared to originate from this strand. The patient's progress was uneventful. There was no post-operative muscle weakness, reflex change or sensory disturbance and there was perfect sphincter control. Examination of the specimen showed a tumour $5 \times 2 \times 2 \mathrm{~cm}$ in size. Histologically it was a typical oligodendroglioma (see Fig. 1). In view of the fact that cerebral oligodendrogliomas sometimes seed into the spinal cord, an X-ray of the skull and an EEG were performed. Both of these were normal. It was, therefore, presumed that this was a primary oligodendroglioma of the spinal cord. cases of secondary oligodendrogliomata of the spinal cord have been reported to date (Bailey \& Hillier, 1924 ; Strang \& Nordenstam, 1961) and three further cases in which there was spinal cord involvement by metatases from intracerebral oligodendrogliomas (Earnest et al., 1950). We felt, therefore, that the present case was worth recording. It also appears to be the first case reported in the literature in the United Kingdom.

Oligodendrogliomas are characteristically very slow-growing with an average duration of about 5 years in the case of cerebral tumours, and one series suggests an average duration of 8-14 years or even longer (Earnest et al., 1950). The intra-

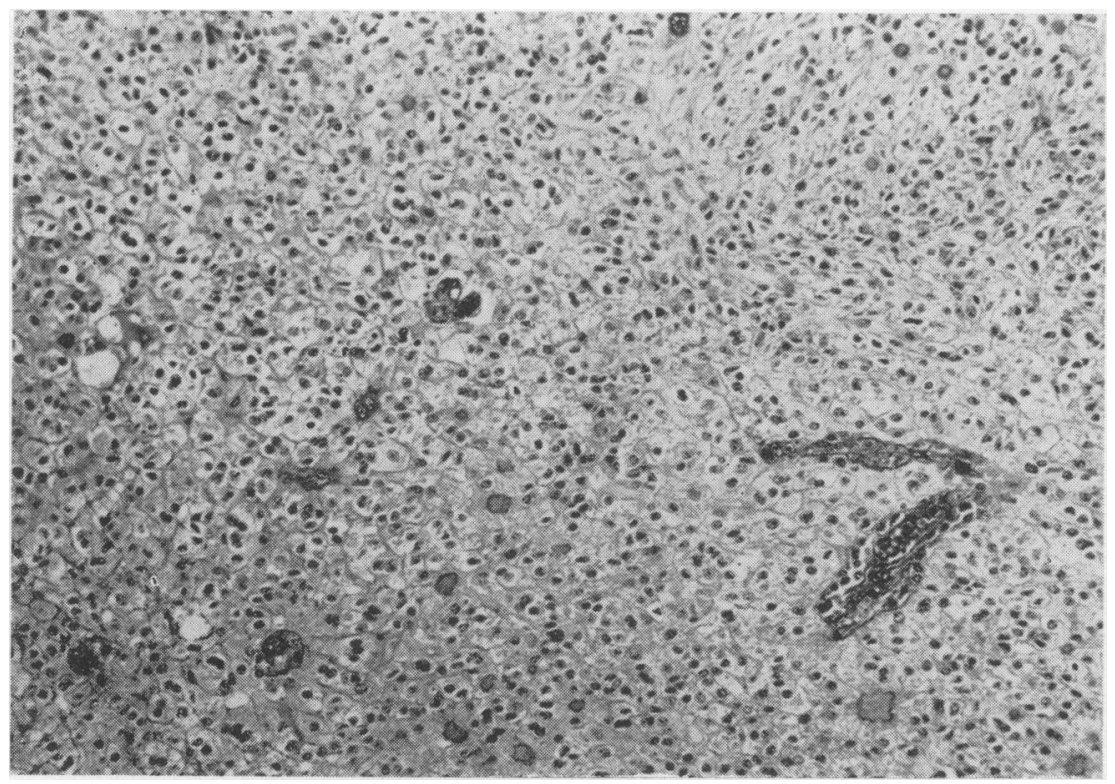

FIG. 1.

\section{Discussion}

In 1924 it was suggested that oligodendrocytes formed part of some intracerebral gliomas (Bailey \& Hillier, 1924). In 1926, tumours consisting entirely of oligodendrocytes were reported (Bailey \& Cushing, 1926). Since then oligodendrogliomas have been accepted as a not too rare type of cerebral tumour, accounting for $3.5 \%$ of gliomas (Russell \& Bucy, 1949). One series reported 200 cases (Earnest, Kernohan \& Craig, 1950). Oligodendrogliomas of the spinal cord, however, are extremely rare. In our search of literature only eleven cases of primary (Kernohan, Woltman \& Adson, 1931, 1933; Oljenick, 1936 ; Rasmussen, Kernohan \& Adson, 1940; Woods \& Pimenta, 1944; Russell \& Bucy, 1949; Eneström \& Gröntoft, 1957; Love \& Rivers, 1962) and two medullary oligodendrogliomata of the spinal cord are also very slow-growing and one case with a survival after 31 years from a primary oligodendroglioma has been reported (Love \& Rivers, 1962).

Macroscopically the tumour is firm, red and fleshy. Microscopically the tumour presents a rather uniform honeycomb appearance consisting of large polyhedral cells with distinct cell membranes. Within the cells the cytoplasm is hardly discernible; the nuclei in contrast are round and very darkly staining. Frequently areas of calcification are seen in oligodendrogliomas. In the spinal cord approximately $30 \%$ occur in the cervical spine, $60 \%$ in the thoracic spine and $10 \%$ in the lumbar spine. The peak age incidence is about $30-40$ years and the sex ratio is equal. Intra- 
medullary tumours are said rarely to produce pain as compared to the frequency with which extramedullary tumours present with pain as an early symptom. The reason for this being that the nerve roots are not involved so frequently in the case of intramedullary tumours. Sensory and motor disturbances are a more common mode of presentation and are steadily progressive until a definite transverse cord lesion with a sensory level is produced. The upper sensory level in intramedullary tumours is less distinct than in extramedullary form. Loss of sphincter control below the level of the lesion occurs early in the intramedullary type (Rasmussen et al., 1940).

The prognosis of an intramedullary oligodendroglioma is probably better than in other forms of intramedullary spinal tumours since it is so slow-growing. An intramedullary tumour discovered at operation need not be considered inoperable (Woods \& Pimenta, 1944). It is often impossible to differentiate extramedullary from intramedullary tumours prior to operation.

\section{Summary}

A case of a primary spinal oligodendroglioma is reported. This is a rare tumour and in our search of literature we found only eleven previously reported cases. The patient presented as a case of attempted suicide.

\section{Acknowledgments}

We should like to express our thanks to Dr J. D. Williams and $\mathrm{Mr}$ G. B. Northcroft for allowing us to report this case.

\section{References}

Bailey, P. \& Cushing, H. (1926) A Classification of the Tumours of the Glioma Group on a Histogenetic Basis with a Correlated Study of Prognosis, p. 175. Lippincott, Philadelphia.

Bailey, P. \& Hillier, G. (1924) The interstitial tissues of the central nervous system; a review. J. nerv. ment. Dis. 59, 337.

Earnest, F., Kernohan, J.W. \& Craig, W.McK. (1950) Oligodendrogliomas-A review of 200 cases. Arch. Neurol. Psychiat. (Chic.), 63, 964.

Enestrom, S. \& Grontoft, O. (1957) Oligodendroglioma of the spinal cord. Acta path. microbiol. scand. 11, 396.

Kernohan, J.W., Woltman, H.W. \& Adson, A.W. (1931) Intramedullary tumours of the spinal cord. Arch. Neurol. Psychiat. (Chic.), 25, 679.

Kernohan, J.W., Woltman, H.W. \& Adson, A.W. (1933) Gliomas arising from the region of the cauda equina; clinical, surgical and histologic considerations. Arch. Neurol. Psychiat. (Chic.), 29, 287.

Love, J.G. \& Rivers, M.H. (1962) 31 year cure following removal of intramedullary glioma of cervical portion of spinal cord. J. Neurosurg. 19, 906.

OlJENick, I. (1936) Intramedullaire Gezwellen. Ned. T. Geneesk. 80, 1335.

Rasmussen T.B., Kernohan, J.W. \& Adson, A.W. (1940) Pathologic classification with surgical consideration of intraspinal tumours. Ann. Surg. 3, 513.

Russell, J.R. \& BuCY, P.C. (1949) Oligodendroglioma of the spinal cord. J. Neurosurg. 6, 433.

Strang, R.R. \& Nordenstam, H. (1961) Intracerebral oligodendroglioma with metastatic involvement of the caude equina. J. Neurosurg. 18, 683.

Woods, W.W. \& Pimenta, A.M. (1944) Intramedullary lesions of the spinal cord-Study of 68 consecutive cases. Arch. Neurol. Psychiat. (Chic.), 52, 383.

\section{Phenacetin nephropathy in a patient with an ileostomy}

\author{
N. H. DYER* \\ M.A., M.B., M.R.C.P. \\ Medical Registrar
}

\author{
F. I. LEE $\dagger$ \\ M.B., M.R.C.P. \\ Senior Medical Registrar
}

The London Hospital, London, E.1

\begin{abstract}
An ASSOCIATION between excessive ingestion of analgesic compounds containing phenacetin and renal damage is established (Spühler \& Zollinger, 1953). Moeschlin (1958) estimated that there were 20,000 analgesic abusers in Switzerland and in Denmark $29 \%$ of hospital in-patients take phenacetin each day (Larsen \& Moller, 1959). In Finland, $20 \%$ of in-patients and $10 \%$ of factory

\footnotetext{
* Present post: Research Registrar, St Bartholomew's Hospital, London, E.C.1.

†Present post: Physician, Victoria Hospital, Blackpool, Lancs.
}

workers ingest analgesic compounds daily (Kasanen, Forsström \& Salmi, 1962). The extent of the problem in the United Kingdom has probably been underestimated. Prescott (1966) found that abuse of analgesics was common in north-east Scotland, and that it was the cause of considerable morbidity and mortality from renal disease. He also commented on some unusual reasons for this abuse. We report here a patient who took an analgesic compound for the constipating effect of its codeine content, and in whom phenacetin nephropathy developed. 